\title{
Isolation and identification of petroleum degrading bacteria from oil contaminated soil \& water and assessment of their potentiality in bioremediation
}

\author{
Tazeena Hassan Islam ${ }^{1}$, Badal Ghosh ${ }^{1}$, Md. Mehedi Hasan Magnet, \\ Kaniz Fatema ${ }^{1}$, Selina Akter ${ }^{1+2}$, Md.Abdur Rahim Khan ${ }^{1+3}$, Suvamoy Datta $^{1 *}$ \\ ${ }^{1}$ Department of Microbiology, Primeasia University, Bangladesh \\ ${ }^{2}$ Department of Microbiology, Jessore Science and Technology University, Bangladesh \\ ${ }^{3}$ Essence Homoeopathy Medical Center, 7/A Shobhanbag, Sher-e-Bangla Nagar, Dhaka
}

\begin{abstract}
Oil spillage has become a global environmental problem. Natural bioremediation is the only ecofriendly solution to resist its devastating environmental and economic damage damage. In this investigation, petroleum tolerant and degrading bacteria were isolated from different oil-contaminated soil and water samples. Bushnell Haas media supplemented with petrol, kerosene, and diesel as sole carbon sources was used for isolation of bacteria capable of degrading these petroleum fractionates. From three soil samples and two water samples, a total of nine bacterial strains were isolated capable of degrading petrol, kerosene and diesel with varying tolerance capacities. The isolates were identified by using standard biochemical tests and morphological studies, and it was determined that these strains belong to six bacterial genera e.g., Staphylococcus, Micrococcus, Streptococcus, Bacillus, Klebsiella and Corynebacterium. The isolated Staphylococcus spp. were found to be the most tolerant isolate withstanding as high as 7\% petroleum. The others also exhibit tolerance to varying concentrations of petroleum. All these isolates were able to degrade petroleum completely and produced $\mathrm{CO}_{2}$ within 7 days, with a few exceptions for Bacillus sp. and Klebsiella sp. which required 15 days for complete degradation of kerosene. These isolates seemed to have potential for bioremediation of oil contaminated soil and water.
\end{abstract}

Keywords : Bioremediation, Degradation, Petroleum, Staphylococcus spp., Tolerance

\section{Introduction}

Petroleum enters into the environment through waste disposal, accidental spills, leakage tankers and losses during transport or storage [1]. The extensive use of petroleum products leads to the contamination of almost all compartments of the environment, and biodegradation of the hydrocarbons by natural populations of microorganisms has been reported to the main process acting in the depuration of the hydrocarbon-polluted environments [2]. Annually, around 6 million tons of crude oil from oily compounds enters global environments, which not only cause human health hazard, but also damage our surrounding environment [3].

The toxic effects of crude oil and refined petroleum oils on plants, animals, humans and the environment are devastating [4]. Oil toxicity is caused by the soluble fraction, which consists of low boiling point aromatic hydrocarbon including benzene, toluene, zylene, naphthalene, pentrathene etc. Oil pollution has been recognized as one of the most serious problems for biotic life. Due to exposure to high oil concentrations, kidney and liver diseases might develop, cancer is enhanced, and it might also damage bone marrow.

Petroleum hydrocarbon is composed of carbon and hydrogen. Many microorganisms have the ability to utilize petroleum as sole source of carbon as energy for metabolic activities, and these microorganisms are widely present and distributed in nature [5]. Bioremediation, which is the removal of organic pollutants from the environment by microorganisms, is one of the best approaches for restoring contaminants of soil and water.

Bioremediation processes rely on the ability of microorganisms present naturally which are highly efficient due to their simplicity and cost effectiveness when compared to other technologies. The process of bioremediation is defined as the use of microorganism to detoxify or remove pollutants, which relies upon microbial enzymatic activities to transform or degrade offending contaminants. It is an evolving method for the removal and destruction of many environmental pollutants [6]. Research and application of bioremediation on soil environment has been started in Indonesia [7]; however in marine environment, it is still need to be studied due to more complicated aspects and also difficulties. Therefore comprehensive study in biodegradation processes that involves various factors such as pollutants, microorganisms, energy sources, physical and chemical conditions, toxicity, competition and metabolites accumulation have to be done. Bioremediation of petroleum is a mineralization of organic chemicals, leading ultimately to the formation of $\mathrm{CO}_{2}, \mathrm{H}_{2} \mathrm{O}$ and biomass. Hydrocarbon utilizing microorganisms are ubiquitously distributed in the environment following oil spills [8]. Biodegradation has at least three important processes: first, they cause a minor change in an organic 
molecule leaving the main structure still impact; second, degradation can also be thought of as fragmentation, where the original structure of the molecule can still be recognized in the fragments and finally, a complete mineralization of a compound to inorganic form.

The purpose of this research was to isolate and identify bacteria growing in oil contaminated soils near petrol and diesel filling pumps of Kamalapur railway station, Buriganga river side and water from Buriganga river in Dhaka city to degrade petroleum components (petrol, diesel, kerosene). The population of microorganisms found in oil-polluted environment should degrade petroleum and higher rates than microorganisms in relatively clean environment [9]. Petroleum hydrocarbon utilizing bacteria should also intrinsically tolerate oil contaminated environment because of their extended exposure and the capability to utilize oil as energy source.

\subsection{Sample Collection}

\section{Materials and Methods}

Three soil samples and two water samples were collected from different oil contaminated sites in sterile bottles and polythene bags. Samples were collected in $5 \mathrm{~cm}$ depth from the surface of soil to avoid surface contamination. Water samples were collected in oil contamination site. Collected samples were transferred into the laboratory under sterile condition and stored at $4^{\circ} \mathrm{C}$ until processed for analysis.

\subsection{Isolation of bacterial cultures}

Ten gm of soil and $10 \mathrm{ml}$ water samples were diluted into $90 \mathrm{ml}$ distilled water and prepared dilutions $\left(10^{-3}, 10^{-4}, 10^{-5}\right)$. Then $0.1 \mathrm{ml}$ suspension from each dilution was transferred into nutrient agar plate by using spread plate technique and incubated at $37^{\circ} \mathrm{C}$ for $24 \mathrm{~h}$.

\subsection{Isolation and identification of petroleum degrading bacteria}

Bushnell Haas (BH) agar/broth medium was used for the isolation of petroleum degrading bacteria. This medium contains all nutrients except the carbon source. The medium composition is as follows: $\mathrm{MgSO}_{4}$ $.7 \mathrm{H}_{2} \mathrm{O}(0.2 \mathrm{~g} / \mathrm{L}), \mathrm{K}_{2} \mathrm{HPO}_{4}(1.0 \mathrm{~g} / \mathrm{L}), \mathrm{KH}_{2} \mathrm{PO}_{4}(1.0 \mathrm{~g} / \mathrm{L}), \mathrm{FeCl}_{3}(0.05 \mathrm{~g} / \mathrm{L}), \mathrm{NH}_{4} \mathrm{NO}_{3}(1.0 \mathrm{~g} / \mathrm{L})$ and $\mathrm{CaCl}_{2}(0.02$ $\mathrm{g} / \mathrm{L})$ with $\mathrm{pH}$ 7.2. Agar $(20 \mathrm{~g} / \mathrm{L})$ was added for $\mathrm{BH}$ agar $[10,11]$. The medium was supplemented with petroleum to serve as the only source of carbon and energy. Isolated bacterial cultures were streaked on $\mathrm{BH}$ agar plate and $100 \mu \mathrm{l}$ of petroleum was spread onto the surface of agar plate as sole source of carbon. The plates were incubated at $37^{\circ} \mathrm{c}$ for $2-3$ weeks. After the incubation period, only petroleum degrading bacteria remained on the surface of the plates [12].

The bacterial colonies were then identified by Gram staining and biochemical tests according to Bergey's manual. For more confirmation of petroleum degradation, BH broth medium was used. Isolated bacterial cultures were enriched into peptone broth. $1 \mathrm{ml}$ of enriched culture was added into the test tube containing BH broth, $50 \mu \mathrm{l}$ of petroleum was added as sole source of carbon in each of the tubes. All the test tubes were incubated at $37^{\circ} \mathrm{C}$ for $2-3$ weeks. Petroleum degrading bacteria will produce gas bubbles on the petroleum-water interface, which indicate a positive degradation reaction.

\subsection{Tolerance of Petroleum Concentrations}

Tolerance to petroleum (diesel, petrol, kerosene) concentrations were assessed by the ability of organisms to grow on $\mathrm{BH}$ agar plate into which petroleum (0.1- 7.0\% concentrations) were incorporated. Different concentrations of petroleum containing BH agar plates were inoculated with the isolated cultures. The inoculated agar plates were incubated at $37^{\circ} \mathrm{C}$ for 7 days. After the incubation period, tolerance range of petroleum concentrations of isolated bacteria were obtained on the basis of their growth.

\subsection{Identification of isolates \\ Morphological and biochemical tests were done for identification of isolates}

\section{Results and Discussion}

In this research, we used soil and water samples from different oil contaminated sites for isolation and identification of petroleum degrading bacteria. Isolated bacteria were able to utilize the three petroleum components i.e. petrol, diesel and kerosene tested as their sole carbon source. A total of nine petroleum degrading bacteria were isolated and were identified by standard biochemical tests and morphological studies (Table 1). 
Table 1: Gram reaction and biochemical characterization of petroleum degrading bacterial isolates.

\begin{tabular}{|c|c|c|c|c|c|c|c|c|c|c|c|c|}
\hline \multirow{2}{*}{$\begin{array}{c}\text { Isolate } \\
\text { designation }\end{array}$} & \multirow{2}{*}{$\begin{array}{c}\text { Gram } \\
\text { stain }\end{array}$} & \multirow[t]{2}{*}{ Shape } & \multicolumn{2}{|c|}{$\begin{array}{c}\text { Ferm } \\
\text { entati } \\
\text { on } \\
\end{array}$} & \multirow{2}{*}{$\begin{array}{l}\overrightarrow{\vec{s}} \\
\underline{\Xi} \\
\tilde{\mathbb{I}} \\
\end{array}$} & \multirow{2}{*}{ 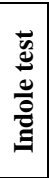 } & \multirow{2}{*}{$\begin{array}{l}\overrightarrow{\vec{z}} \\
\stackrel{\underline{z}}{z} \\
\stackrel{y}{z}\end{array}$} & \multirow{2}{*}{ 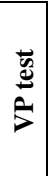 } & \multirow{2}{*}{ 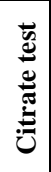 } & \multirow{2}{*}{ 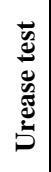 } & \multirow{2}{*}{ 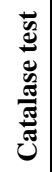 } & \multirow[t]{2}{*}{ Presumptive Organism } \\
\hline & & & 롤 & 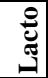 & & & & & & & & \\
\hline Psw & $\mathrm{G}(+)$ & Cocci & - & + & - & - & + & - & - & - & - & Streptococcus spp. \\
\hline Psy & $\mathrm{G}(+)$ & Cocci & - & - & - & - & - & - & - & + & + & Micrococcus spp. \\
\hline Rsw & $\mathrm{G}(+)$ & Cocci & - & - & - & - & - & - & - & + & + & Micrococcus spp. \\
\hline Rsy & $\mathrm{G}(+)$ & Cocci & + & - & - & - & + & + & - & - & + & Staphylococcus spp. \\
\hline Ksw & $\mathrm{G}(+)$ & Cocci & + & - & - & - & + & + & - & - & + & Staphylococcus spp. \\
\hline Ksy & $\mathrm{G}(+)$ & Cocci & + & - & - & - & + & - & - & - & + & Staphylococcus spp. \\
\hline Saw & $\mathrm{G}(+)$ & Rod & + & - & - & - & - & + & - & - & + & Bacillus spp. \\
\hline Say & $\mathrm{G}(-)$ & Rod & - & + & - & - & + & + & + & + & + & Klebsiella spp. \\
\hline Suw & $\mathrm{G}(+)$ & Rod & + & - & - & - & - & - & - & - & + & Corynebacterium spp. \\
\hline Suy & $\mathrm{G}(-)$ & Rod & + & + & - & + & + & - & - & - & + & Escherichia spp. \\
\hline
\end{tabular}

On the basis of these studies, it was determined that these strains belong to six bacterial genera e.g., Staphylococcus, Micrococcus, Streptococcus, Bacillus, Klebsiella and Corynebacterium. All these isolates were found to grow effectively on BH agar supplemented with different petroleum fractionates (Fig. 1). In BH broth, those isolates were found to degrade petroleum with $\mathrm{CO}_{2}$ production within 7 days, except for Bacillus sp. and Klebsiella sp. which required 15 days for degradation of kerosene (Fig. 2).

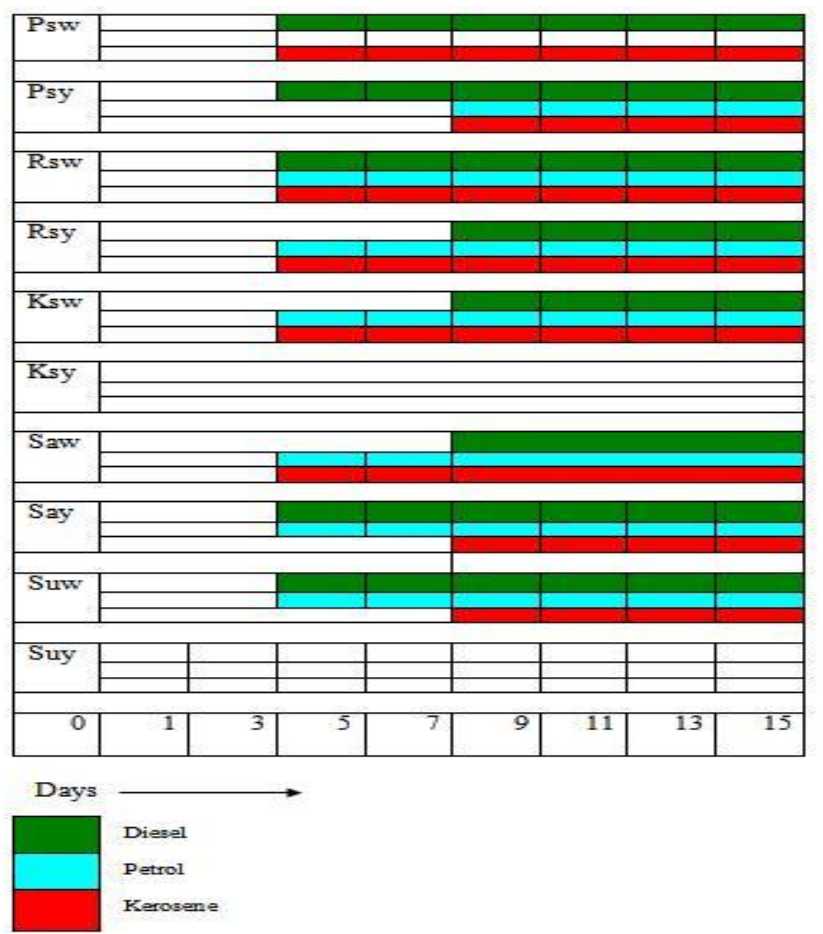

Figure 1: Graphical representation for the growth of different isolates on BH agar with different petroleum fractionates as sole carbon source. The $\mathrm{X}$-axis designates the days of incubation and in the $\mathrm{Y}$-axis designates test isolates.

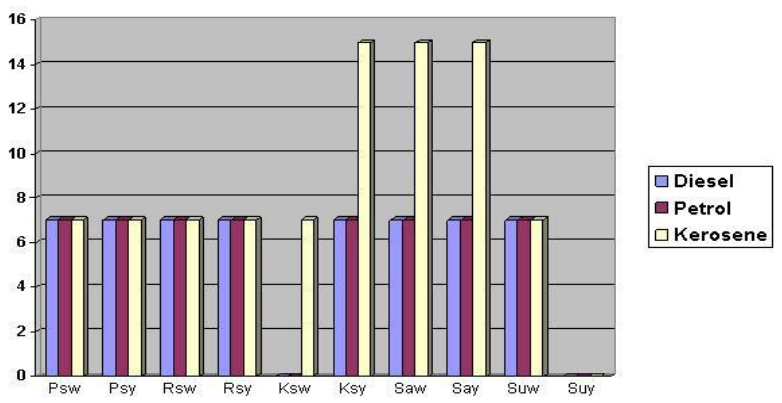


Figure 2: Graphical representation for the degradation of different isolates on BH broth with a layer of different petroleum fractionates as sole carbon source. The $\mathrm{Y}$-axis designates the days of incubation. The positive degradation was observed by the accumulation of gas $\left(\mathrm{CO}_{2}\right)$ bubbles at the media-petroleum interface.

Petroleum degrading bacteria also shows tolerance to considerable concentrations of petroleum, which is a vital criterion to act in bioremediation of highly polluted environments. All the test isolates were also found to tolerate petrol, diesel and kerosene in different concentrations ranged between 0.1 and 7\% (Fig. 3). The Staphylococcus spp. was found to be the most tolerant withstanding as high as $7 \%$ of petroleum. All these isolates could be potentially used for bioremediation purposes for cleaning up oil polluted area.

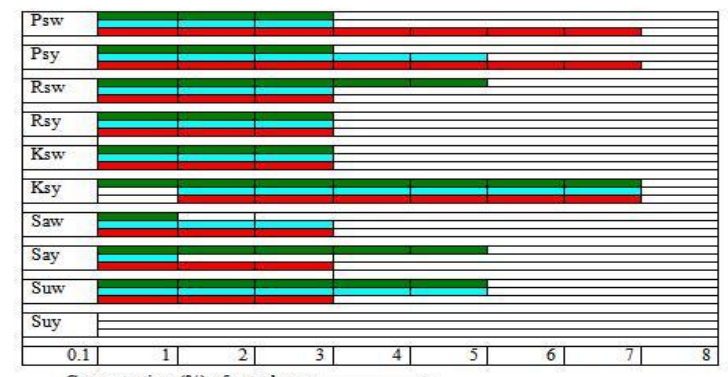

$$
\text { Concentrations }(\%) \text { of petroleum } \longrightarrow
$$

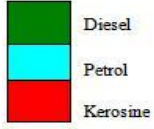

Figure 3: Graphical representation for the growth of different isolates on BH agar with different petroleum fractionates as sole carbon source. The $\mathrm{X}$-axis designates the days of incubation and in the Y-axis designates test isolates.

\section{Conclusion}

In this study, three petroleum degrading bacterial genera e.g., Micrococcus, Staphylococcus, Streptococcus were isolated from soil. The other three genera e.g., Bacillus, Klebsiella and Corynebacterium were isolated from water. A Staphylococcus sp. isolated from Kamalapur soil was found to tolerate the highest concentrations (7\%) of petroleum, therefore can be used potentially to decontaminate oil spillage from water and soil. Both Gram positive and negative bacterial genera were isolated and assumed to have a common pattern of tolerance and degradation of petroleum.

\section{References}

[1] O.I. Anthony, Biodegradation alternative in the cleanup of petroleum hydrocarbon pollutants. Biotechnology and Molecular Biology Review, 1(2), 2006, 38-50.

[2] F. Chaillan, A. Le-Fleche, E. Bury, Y. Phantavong, P. Grimont, A. Saliot, J. Oudot, Identification and biodegradation potential of tropical aerobic hydrocarbon-degrading microorganisms, Res. Microbiol. 155, 2004, 587-595.

[3] D. Maola, A. Taher, E. Elham, Review of the feasibility of inoculation situ biological therapy techniques to reduce pollution at the Shiraz refinery lands using Taguchi Method. University of Chemical Engineering, Oil and Gas, Shiraz University, 2002, 637-627.

[4] D. Elliot, Power resources; Technology; Environmental aspects; Social aspects (Routledge, London 1997).

[5] S.Y.T. Adeline, H.C.T. Carol, C.S. Aw, Hydrocarbon-degradation by isolate Pseudomonas lundensis UTAR FPE2. Malaysian Journal of Microbiology, 5(2), 2009, 104-108.

[6] J.C. Philp, R. M. Atlas, Bioremediation of contaminated soils and aquifiers, In R.M. Atlas and J.C.Philp (ed.), Bioremediation Applied Microbial Solutions for Real-World Environmental Cleanup (ASM Press, Washington, D.C. 2005) 139-236.

[7] P. Aditiawati, D. Indriani, N.P. Aryantha., Production of biosurfactan by hydrocarbonoclastic bacteria for oil spills bioremediation. Report on Competitive Grant. Microbiology Laboratory - Biology Department, ITB, Bandung, 2001.

[8] M. Dua, A. Singh, N. Sathunathan, A.K. Johri, Biotechnology and Bioremediation: Success and Limitations, Appl. Microbiol. Biotechnol. 59(2-3), 2002, 143- 152.

[9] O. Obire, I.V. Okudu, Effect of crude oil on a fresh water stream in nigeria. J. Appl. Sci. Environ. Management, 9, 1997, 25-32.

[10] L.D. Bushnell, H.F. Haas, The utilization of certain hydrocarbons by microorganisms. J. Bacteriol., 41, 1941, 653-653

[11] Allred, DeGray, Edwards, Hedrick, Klemme, Rogers, Wolf and Hodge, Proposed procedures for Microbiological examination of fuels, (SIM special publication, No. 1. Merck, Sharp \& Dohme Research Laboratories, Rahway, N.J. 1963).

[12] M.R. Atlas, B. Richard, Microbiology ecology, fundamentals and application. Microbiol. Interaction Xenobiotic Inorganic Pollut., 13(511), 1946, 517-529. 